\title{
Modulation of Inhibitory Transmission by Dopamine in Rat Basal Forebrain Nuclei: Activation of Presynaptic $D_{1}$-like Dopaminergic Receptors
}

\author{
Toshihiko Momiyama ${ }^{1}$ and J. A. Sim ${ }^{2}$ \\ ${ }^{1}$ Department of Pharmacology, University College London, London WC1E 6BT, United Kingdom, and 'Department of \\ Neurobiology, Babraham Institute, Cambs CB2 4AT, United Kingdom
}

The effects of dopamine (DA) on inhibitory transmission onto identified magnocellular neurons were examined in rat basal forebrain slices using whole-cell recording. IPSCs evoked by focal stimulation within basal forebrain nuclei were reversibly blocked by $10 \mu \mathrm{M}$ bicuculline and had a decay time constant of $20.1 \pm 0.77 \mathrm{msec}$ in the presence of 6-cyano-7nitroquinoxalline-2,3-dione $(5 \mu \mathrm{M})$. Bath application of DA reduced the amplitude of IPSCs up to $71.1 \pm 1.49 \%$ in a concentration-dependent manner between 0.003 and $1 \mathrm{~mm}$ (the $\mathrm{IC}_{50}$ value being $\left.6.6 \mu \mathrm{M}\right)$, without any effect on the holding current at $-70 \mathrm{mV}$. DA $(10 \mu \mathrm{m})$ reduced the frequency of miniature IPSCs (mIPSCs) recorded in the presence of TTX $(0.5$ $\mu \mathrm{M})$, without affecting their mean amplitude, rise time, and decay time constant. Furthermore, the DA-induced effect on mIPSCs remained unaffected by $100 \mu \mathrm{M}$ cadmium, suggesting a presynaptic mechanism independent of calcium influx. SKF 81297, a $D_{1}$-like agonist, mimicked DA-induced effect on evoked IPSCs $\left(\mathrm{IC}_{50}, 10.9 \mu \mathrm{M}\right)$, whereas $\mathrm{R}(-)$-TNPA or (-)quinpirole, $D_{2}$-like agonists $(30 \mu \mathrm{M})$, had little or no effect on the amplitude of evoked IPSCs. $\mathrm{R}(+)-\mathrm{SCH} 23390$, a $\mathrm{D}_{1}$-like antagonist, antagonized the DA-induced effect on IPSCs $\left(K_{\mathrm{B}} 0.82\right.$ $\mu \mathrm{M})$, whereas $\mathrm{S}(-)$-eticlopride, a $\mathrm{D}_{2}$-like antagonist, showed slight antagonism $\left(K_{\mathrm{B}} 7.8 \mu \mathrm{M}\right)$. Forskolin $(10 \mu \mathrm{M})$ reduced the amplitude of evoked IPSCs to $\sim 58 \%$ of the control and occluded the inhibitory effect of DA. These findings indicate that DA reduces inhibitory transmission onto magnocellular basal forebrain neurons by activating presynaptic $D_{1}$-like receptors.

Key words: dopamine; $D_{1}$ receptor; inhibitory postsynaptic currents; magnocellular basal forebrain nuclei; presynaptic modulation
Magnocellular basal forebrain (MBF) neurons in the vertical and horizontal limbs of diagonal band of Broca (HDBB), substantia innominata $(\mathrm{SI})$, and nucleus basalis $(\mathrm{nB})$ form the principal source of cholinergic innervation to the cerebral and subcortical brain regions (Rye et al., 1984). Pathophysiologically, degeneration of these cholinergic neurons has been observed in patients with Alzheimer's disease (Coyle et al., 1983; Oyanagi et al., 1989), yet the question of how these cortically projecting neurons can be influenced remains to be clarified. Morphological studies using immunohistochemical techniques have demonstrated that the basal forebrain region receives dopaminergic fibers from the ventral tegmental area, substantia nigra pars compacta, and medial zona interna (Martinez-Murillo et al., 1988; Semba et al., 1988; Eaton et al., 1994). Despite these well documented pathways, the basic effects of dopamine (DA) on synaptic transmission within basal forebrain nuclei are still not well understood. Previous electrophysiological studies using anesthetized rats have shown that neuronal activity is variably inhibited or excited by iontophoretic application of DA in other groups of basal forebrain nuclei, namely the globus pallidus (Bergstrom and Walters, 1984) and ventral pallidum (Napier and Maslowski-Cobuzzi,

\footnotetext{
Received July 8, 1996; revised Sept. 10, 1996; accepted Sept. 16, 1996.

This work was supported by grants from The Wellcome Trust (T.M.) and the Medical Research Council (J.A.S). We are grateful to Professor D. A. Brown (University College London) for his helpful discussion. We are also grateful to Dr. Stephen F. Traynelis (Emory University) for the software to analyze miniature IPSCs.

Correspondence should be addressed to Dr. Toshihiko Momiyama at his present address: Department of Physiology, Nagasaki University School of Medicine, 1-12-4 Sakamoto, Nagasaki 852, Japan.

Copyright (C) 1996 Society for Neuroscience $0270-6474 / 96 / 167505-08 \$ 05.00 / 0$
}

1994). Our recent studies (Momiyama et al., 1995a; 1996) showed that DA reduces excitatory synaptic transmission onto visualized magnocellular neurons within the HDBB, SI, and $\mathrm{nB}$ regions of the rat brain. Furthermore, our pharmacological studies revealed that the action of DA was mediated via the activation of presynaptically located $\mathrm{D}_{1}$-like receptors. Similar reduction of excitatory transmission mediated by presynaptic $\mathrm{D}_{1}$-like receptors has been reported in nucleus accumbens (Pennartz et al., 1992; Harvey and Lacey, 1996; Nicola et al., 1996). In contrast, information regarding the effect of DA on inhibitory synaptic transmission in basal forebrain is sparse, although it has been known that iontophoretic application of DA attenuated the inhibitory action of iontophoretically administered GABA on the firing rates of neurons within the globus pallidus (Bergstrom and Walters, 1984). To further understand the role of DA in basal forebrain nuclei, the present study examined the effect of DA on the inhibitory synaptic transmission onto visualized MBF neurons using the whole-cell patch-clamp technique in a thin-slice preparation of the rat brain. The identity of the DA receptor family involved was studied using pharmacologically selective agonists and antagonists.

Preliminary data from these studies have been published previously in abstract form (Momiyama et al., 1995b).

\section{MATERIALS AND METHODS}

Preparation and recording procedures. The details of slicing and whole-cell recording procedures were as described previously (Sim and Griffith, 1996). In brief, 12- to 14-d-old rats were decapitated after deep anesthesia with chloroform, and their brains were removed and placed in an ice-cold cutting Krebs solution of the following composition (in mM): 118 $\mathrm{NaCl}, 3 \mathrm{KCl}, 0.5 \mathrm{CaCl}_{2}, 6 \mathrm{MgCl}_{2}, 25 \mathrm{NaHCO}_{3}, 5 \mathrm{HEPES}$, and 11 D-glucose, continuously bubbled with $95 \% \mathrm{O}_{2} / 5 \% \mathrm{CO}_{2}$. Coronal slices 
(200 $\mu \mathrm{m})$ containing the basal forebrain region were prepared using a microslicer (Campden, Loughborough, UK) and incubated in normal Krebs solution of the following composition (in $\mathrm{mM}$ ): $118 \mathrm{NaCl}, 3 \mathrm{KCl}, 2.5$ $\mathrm{CaCl}_{2}, 1.2 \mathrm{MgCl}_{2}, 25 \mathrm{NaHCO}_{3}, 5$ HEPES, 11 D-glucose, $\mathrm{pH}$ 7.2, when bubbled with $95 \% \quad \mathrm{O}_{2} / 5 \% \quad \mathrm{CO}_{2}$ at room temperature $\left(20-23^{\circ} \mathrm{C}\right)$ in a temperature-controlled room for at least $1 \mathrm{hr}$. For recording, a slice was transferred to the recording chamber, held submerged, and superfused continuously with the normal Krebs solution (bubbled with $95 \% \mathrm{O}_{2} / 5 \%$ $\mathrm{CO}_{2}$ ) at a rate of $6 \mathrm{ml} / \mathrm{min}$.

Patch electrodes were pulled from thin-walled borosilicate glass capillaries (1.5 mm outer diameter; Clark Electromedical, Reading, UK) and had resistances of 5-8 $\mathrm{M} \Omega$ when filled with a potassium acetate-based internal solution of the following composition (in $\mathrm{mM}$ ): 108 potassium acetate, $15.6 \mathrm{KCl}, 40$ HEPES, $1 \mathrm{MgCl}_{2}, 2$ BAPTA, $4 \mathrm{Na}_{2} \mathrm{GTP}, 0.1$ MgATP, $0.2 \mathrm{CaCl}_{2}$ (for nominal $\left[\mathrm{Ca}^{2+}\right]_{\mathrm{i}}$ of $30 \mathrm{nM}$, see Sim and Griffith, 1996), and $\mathrm{pH}$ adjusted to 7.2 with $12 \mathrm{~mm} \mathrm{NaOH}$. Whole-cell recordings were made using an Axopatch 200A (Axon Instruments, Foster City, CA) from visually identified MBF neurons viewed with the aid of a microscope (Microtec-2A, Micro Instruments, Oxford, UK) fitted with Hoffmanmodulation optics. The morphological characteristics of these neurons were as follows: large diameter $(>20 \mu \mathrm{m})$ of the soma, with a triangular, fusiform, or multipolar shape (Sim, 1994). Stimulating electrodes were pulled from theta glass (Clark Electromedical, Reading, UK) and filled with normal Krebs solution. Inhibitory synaptic responses were evoked by careful placement of a stimulating electrode within a $50-150 \mu \mathrm{m}$ radius of the recorded cell (the mean distance between the stimulating electrode and the nearest edge of the recorded cell being $70.7 \pm 2.69 \mu \mathrm{m} ; n=83$ cells). A voltage pulse $(0.2-0.4 \mathrm{msec}$ in duration) was applied at a frequency of $0.1 \mathrm{~Hz}$ with suprathreshold intensity. A glass bridge reference electrode containing $4 \%$ agar-saline was used as described previously (Sim and Griffith, 1996). Experiments were carried out at room temperature $\left(20-26^{\circ} \mathrm{C}\right)$.

Data were collected $(10 \mathrm{kHz}$ sampling rate and low-pass-filtered at 3-10 kHz with an 8-pole Bessel filter) using pClamp6 (Axon Instruments) software and digitized at $10-20 \mathrm{kHz}$ for computer analysis. Synaptic currents were routinely evoked at $0.1 \mathrm{~Hz}$, and all traces shown are the averages of 10 traces, with their respective SD. In the present study, IPSCs are inwardly directing; the reversal potential for chloride ions was set at $-54 \mathrm{mV}$, and recordings were made from a holding potential of $-70 \mathrm{mV}$. For experiments studying mIPSCs, data were digitized continuously at $10-20 \mathrm{KHz}$ and stored on a computer. mIPSCs were detected using software generously provided by Dr. Stephen F. Traynelis (Emory University, Atlanta, GA). Curve-fitting was carried out using "Graphpad Inplot" computer software (Graphpad, San Diego, CA). Data are expressed as mean \pm SEM. Statistical analysis was performed using Student's $t$-test (two-tailed) or a nonparametrical Mann-Whitney test, where appropriate; $p<0.05$ was considered statistically significant.

Drugs and their application. All drugs were bath-applied. Dopamine (Sigma, St Louis, MO), ( \pm )-6-chloro-7,8-dihydroxy-1-phenyl-2,3,4,5-tetrahydro1H-3-benzazepine hydrobromide (SKF 81297; Research Biochemicals, Natick, MA), R(-)-2,10,11-trihydroxy- $N$-propyl-noraporphine hydrobromide (TNPA; Research Biochemicals), trans-(-)-4aR-4,4a,5,6,7,8,8a,9octahydro-5-propyl-1H-pyrazolo[3,4 gm]quinoline $((-)$-quinpirole $), \mathrm{R}(+)-$ 7-chloro-8-hydroxy-3-methyl-1-phenyl-2,3,4,5-tetrahydro-1H-3-benzazepine hydrochloride (SCH 23390, Research Biochemicals), S(-)-3-chloro-5-ethyl$N$-[(1-ethyl-2-pyrrolidinyl)methyl]-6-hydroxy-2-methoxy-benzamide hydrochloride (eticlopride; Research Biochemicals), bicuculline (Sigma), and tetrodotoxin (TTX; Sigma) were prepared as $10 \mathrm{~mm}$ stock solutions in distilled water and kept frozen. 6-cyano-7-nitroquinoxalline-2,3-dione (CNQX; Tocris Cookson, Bristol, UK), forskolin (Sigma), and 1,9-dideoxyforskolin (Sigma) were dissolved as $10 \mathrm{~mm}$ stock in dimethylsulfoxide (Sigma). Stock solutions were diluted to the final concentrations in normal Krebs solution just before each experiment. Antagonists were applied at least 10-15 min before the addition of agonist in the continuing presence of antagonist.

\section{RESULTS}

\section{General properties of GABAergic IPSCs}

In the present study, whole-cell recordings were made from 114 MBF neurons clamped at $-70 \mathrm{mV}$ (close to their resting membrane potential) (Sim and Griffith, 1996). The mean diameter of the long axis of the neurons was $29.7 \pm 0.42 \mu \mathrm{m}$ (mean \pm SEM, $n=104)$, and the cell capacitance was $41.8 \pm 1.10 \mathrm{pF}(n=114)$.

IPSCs were evoked in MBF neurons by focal stimulation in the
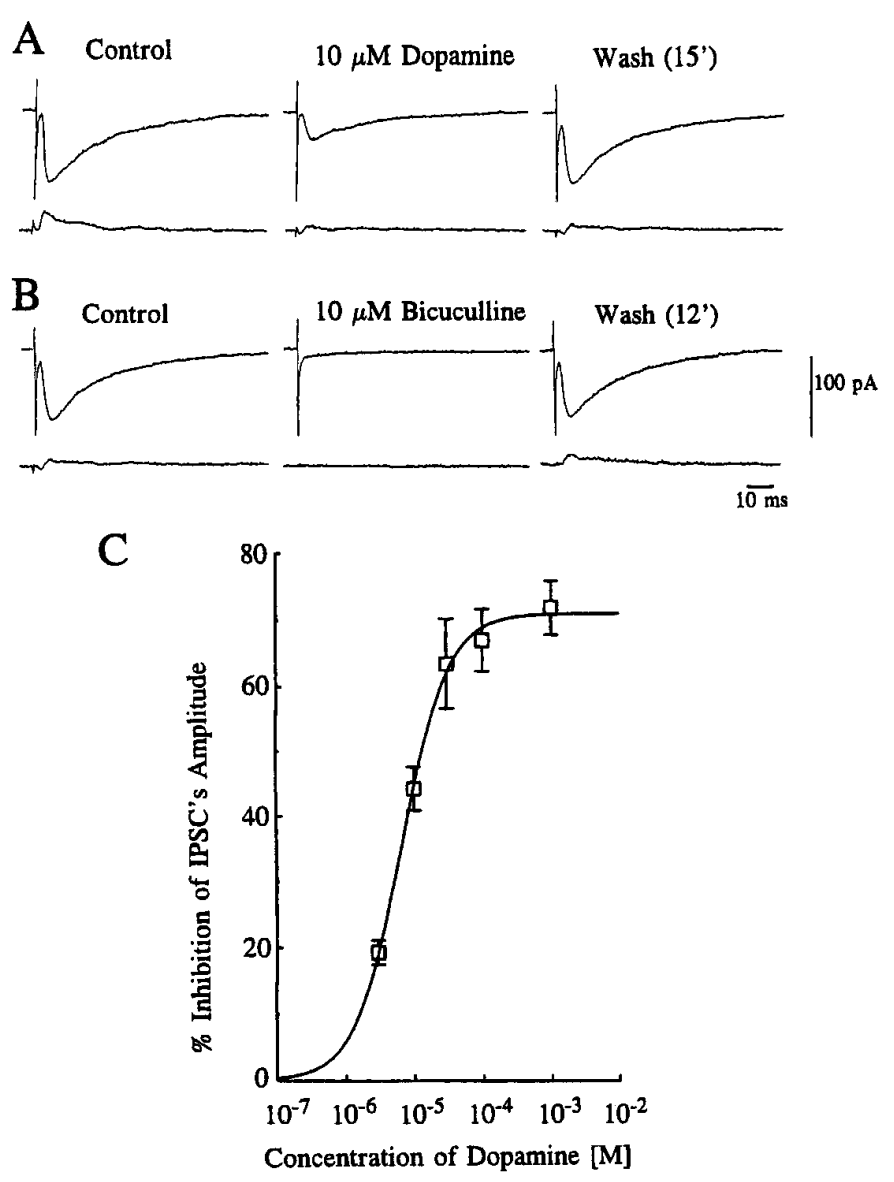

Figure 1. Inhibition of GABAergic IPSCs by dopamine. IPSCs were evoked at $0.1 \mathrm{~Hz}$ in the presence of CNQX $(5 \mu \mathrm{M})$ to eliminate excitatory glutamatergic components. Traces in $A$ and $B$ show averaged records of 10 consecutive responses (top traces) with their corresponding SD (bottom traces). The holding potential was $-70 \mathrm{mV}$. A, Bath application of Dopamine $(10 \mu \mathrm{M})$ produced a $61 \%$ reduction of the amplitude of evoked IPSCs in this cell after $3 \mathrm{~min}$, and its effect was reversed after $15 \mathrm{~min}$ wash. $B$, Reversible suppression of IPSCs by a $\mathrm{GABA}_{\mathrm{A}}$ receptor antagonist, bicuculline $(10 \mu \mathrm{M})$, in the same cell, after recovery from DA-induced effect. The effect of bicuculline recovered after $12 \mathrm{~min}$ wash. Note that the IPSCs are depicted as inward currents, because the equilibrium potential for chloride ions was $-54 \mathrm{mV}$, and cells held at $-70 \mathrm{mV}$. $C$, Concentration-dependent inhibition of evoked IPSCs by DA. Each point shows the mean \pm SEM of data pooled from 4-19 cells. The estimated $\mathrm{IC}_{50}$ value, maximum inhibition, and Hill slope value were $6.6 \mu \mathrm{M}, 71.1 \pm$ $1.49 \%$, and 1.28 , respectively.

presence of $5 \mu \mathrm{M}$ CNQX to eliminate excitatory components. In contrast to EPSCs, IPSCs were evoked less frequently (cf. Sim and Griffith, 1996) in MBF neurons, because the placement of the stimulating electrode seemed to be more critical in eliciting IPSCs than EPSCs. After successful placement of the stimulating electrode, IPSCs were evoked in an "all-or-none" manner around the threshold of stimulation intensity, suggesting that they were monosynaptic in origin (Stern et al., 1992; Takahashi, 1992; Jonas et al., 1993). The amplitude and time constant of the decay phase of evoked IPSCs in 82 neurons were $-86.4 \pm 6.52 \mathrm{pA}$ and $20.1 \pm$ $0.77 \mathrm{msec}$, respectively.

\section{Effect of dopamine on evoked IPSCs}

Figure $1 A$ shows the effect of DA on the amplitude of evoked IPSCs recorded in the presence of $5 \mu \mathrm{M}$ CNQX. Bath application of $10 \mu \mathrm{M}$ DA (for $5 \mathrm{~min}$ ) produced a gradual decline in the 
A

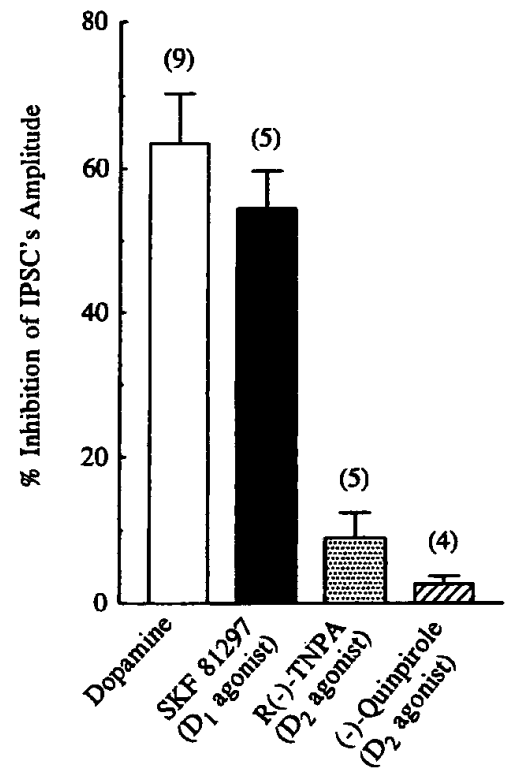

B

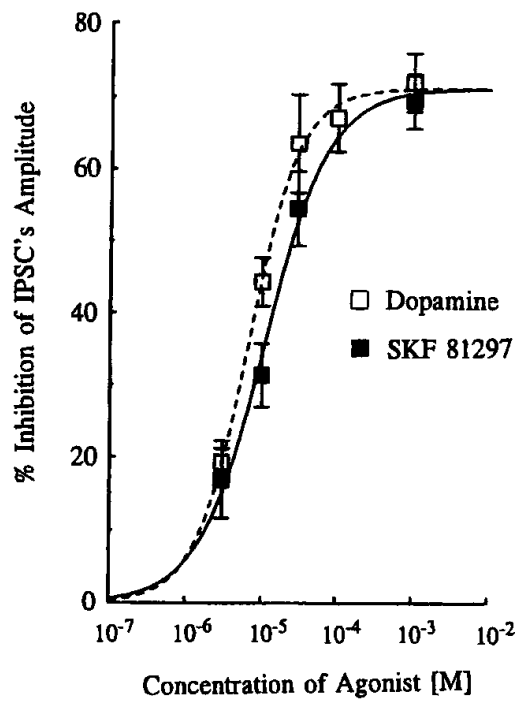

Figure 2. Effect of dopamine receptor agonists on evoked IPSCs. $A$, Summary histograms showing the mean \pm SEM of the inhibitory effects of DA (Dopamine), $S K F$ 81297, R(-). TNPA, and (-)-Quinpirole on the amplitude of evoked IPSCs. All agonists were applied at $30 \mu \mathrm{M}$ concentration. Values for DA, SKF 81297, R(-)-TNPA, and (-)-quinpirole were $63.5 \pm 6.8 \%(n=9), 54.5 \pm 5.2 \%(n=5), 8.9 \pm 3.5 \%(n=$ $5)$, and $2.6 \pm 1.1 \%(n=4)$, respectively. (The value for DA was derived from the concentration-response curve in Fig. 1, and for SKF 81297 from the concentration-response curve in B.) Application of either R(-)-TNPA or (-)-quinpirole had little effect $(p<0.01)$ on inhibition of the amplitude of IPSCs, compared with DA or SKF 81297. The difference between DA and SKF 81297 or R(-)-TNPA and (-)quinpirole was not significant $(p>0.27$ or $p>0.07$, respectively). $B$, Concentration-response curve for the inhibition of IPSC amplitude by DA (open squares, reproduced from Fig. 1) and SKF 81297 (closed squares). Each point represents the mean \pm SEM of pooled data from 3-19 cells. The estimated $\mathrm{IC}_{50}$ value and Hill slopes for SKF 81297 were $10.9 \mu \mathrm{M}$ and 1.02 , respectively. Note that the maximum effect of SKF 81297 was constrained to that of DA. amplitude of the evoked IPSCs, reaching a maximum level 3 min after the onset of application. The effect of DA was reversed after 10-20 min washout. The GABAergic nature of these IPSCs was confirmed when they were reversibly blocked by bath application of $10 \mu \mathrm{M}$ bicuculline, a $\mathrm{GABA}_{\mathrm{A}}$ receptor antagonist (Fig. $1 B$ ). DA-induced inhibitory effects on evoked IPSCs were concentration-dependent between 0.003 and $1 \mathrm{~mm}$. Figure $1 C$ depicts the concentration-response curve pooled from 47 neurons (Fig. $1 C$ ), giving an apparent $\mathrm{IC}_{50}$ value, mean maximum effect, and Hill slope value of $6.6 \mu \mathrm{M}, 71.1 \pm 1.49 \%$, and 1.28 , respectively. No desensitization was observed when DA was applied repeatedly after 10-20 min washout intervals. DA applied at concentrations up to $1 \mathrm{~mm}$ had no effect on the holding current or decay time constant at a holding potential of $-70 \mathrm{mV}$.

\section{Pharmacology of DA-induced inhibition of evoked IPSCs}

To investigate the subtypes of DA receptor mediating DAinduced inhibition of evoked IPSCs, we examined both the action of selective DA receptor agonists on the amplitude of evoked IPSCs (Fig. 2) and the effect of selective DA receptor antagonists on the concentration-response curve produced by DA (Fig. 3).

\section{Effect of $D A$ receptor agonists}

Figure $2 A$ summarizes the effect of DA agonists, applied at $30 \mu \mathrm{M}$ on the amplitude of evoked IPSCs, and data expressed as the mean percentage $( \pm$ SEM) inhibition were depicted as histograms. Bath application of the selective $\mathrm{D}_{1}$-like receptor agonist SKF 81297 (Andersen and Jansen, 1990) reduced the amplitude of evoked IPSCs by $54.5 \pm 5.2 \%(n=5)$. In contrast, a $\mathrm{D}_{2}$-like agonist R(-)-TNPA (Gao et al., 1990) had little or no effect on the amplitude of evoked IPSCs $(8.9 \pm 3.5 \%$ reduction, $n=5)$. Similarly, another $\mathrm{D}_{2}$-like receptor agonist, (-)-quinpirole (Titus et al., 1983), had little or no effect on the amplitude of evoked IPSCs $(2.6 \pm 1.1 \%, n=4)$ (Fig. $2 A)$. SKF 81297 mimicked the effect of DA and also reduced the IPSC in a concentrationdependent manner between 0.003 and $1 \mathrm{~mm}$ (Fig. 2B). Pooled data from 16 cells yielded an apparent $\mathrm{IC}_{50}$ value of $10.9 \mu \mathrm{M}$ and a Hill slope value of 1.02 (when the mean maximum effect was constrained to that of DA). In addition, we also examined the effect of SKF 81297 in the presence of R(-)-TNPA (both applied at $30 \mu \mathrm{M}$ ) but found no difference from the effect of SKF 81297 alone (data not shown).

\section{Effect of $D A$ receptor antagonist on $D A$-induced inhibition of evoked IPSCs}

The effects of a $\mathrm{D}_{1}$-like receptor antagonist, $\mathrm{R}(+)$-SCH 23390 (Iorio et al., 1983), and a $\mathrm{D}_{2}$-like antagonist, $\mathrm{S}(-)$-eticlopride (Hall et al., 1985), on the concentration-dependent inhibition curve for DA were examined (Fig. 3). Bath application of $10 \mu \mathrm{M}$ $\mathrm{R}(+)-\mathrm{SCH} 23390$ or $\mathrm{S}(-)$-eticlopride alone had no effect on the holding current, amplitude, or time course of evoked IPSCs at $-70 \mathrm{mV}$. In the presence of $10 \mu \mathrm{M} \mathrm{R}(+)-\mathrm{SCH} 23390$, the concentration-response curve for DA was shifted to the right (Fig. $3 A)$, whereas in the presence of $\mathrm{S}(-)$-eticlopride $(10 \mu \mathrm{M})$ only a very small shift of the concentration-response curve was observed (Fig. 3B). Assuming that both $\mathrm{R}(+)-\mathrm{SCH} 23390$ and $\mathrm{S}(-)$ eticlopride behave as competitive antagonists, apparent $K_{\mathrm{B}}$ values of $0.82 \mu \mathrm{M}\left(\mathrm{pK}_{\mathrm{B}} 6.1\right)$ and of $7.8 \mu \mathrm{M}\left(\mathrm{pK}_{\mathrm{B}} 5.1\right)$, respectively, were calculated using the equation of $K_{\mathrm{B}}=[B] /(D R-1)$, where $[B]$ is the concentration of the antagonist and $D R$ (dose-ratio) is the ratio of the mean $\mathrm{IC}_{50}$ values for pooled data in the presence and absence of antagonist.

\section{Effect of forskolin and 1,9-dideoxyforskolin on evoked IPSCs}

$\mathrm{D}_{1}$-like receptors have been classified as those positively coupled with adenylate cyclase activity; therefore, we tested the effect of forskolin (which stimulates adenylate cyclase) on the inhibitory action of DA (Fig. 4). Bath application of forskolin (10 $\mu \mathrm{M})$ alone produced a gradual reduction in the amplitude of evoked IPSCs, reaching a steady level after 10-15 min (Fig. 4A,C). The mean percentage inhibition of evoked IPSCs by $10 \mu \mathrm{M}$ forskolin after a 15 min period was $42.1 \pm 6.8(n=10)$ (Fig. $4 B)$. In contrast, 10 $\mu \mathrm{M}$ 1,9-dideoxyforskolin, the inactive form of forskolin, had little or no effect $(2.4 \pm 1.5 \% ; n=5)$ on the amplitude of evoked IPSCs (Fig. 4A,B). DA $(10 \mu \mathrm{M})$ applied after forskolin had reached its steady state produced no further effect on the amplitude of 
A

- $10 \mu \mathrm{M}$ R(+)-SCH 23390 ( $D_{1}$ antagonist)

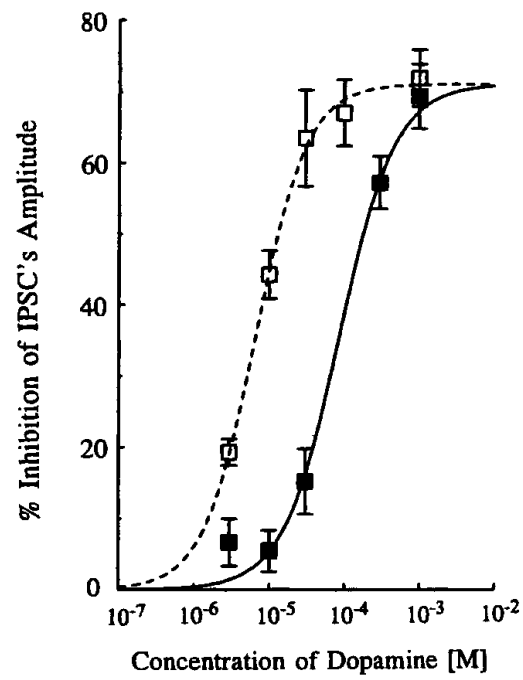

B

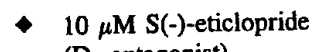
( $D_{2}$ antagonist)

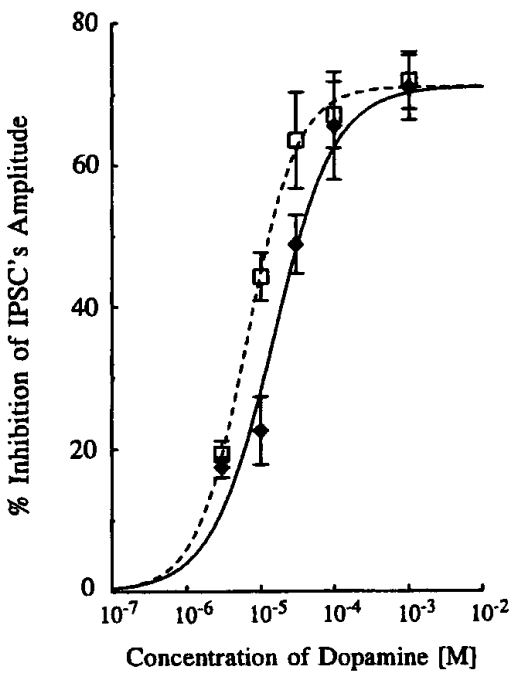

Figure 3. Effects of dopamine receptor antagonists on dopamine-induced inhibition of evoked IPSCs. $A$, Concentration-response curves for IPSC inhibition by DA in the absence (open squares) and presence (closed squares) of $10 \mu \mathrm{M} \mathrm{R}(+)-$ SCH 23390 (a $\mathrm{D}_{1}$-like receptor antagonist). The resultant curve in the presence of $\mathrm{R}(+)-\mathrm{SCH} 23390$ was shifted to the right, with an $\mathrm{IC}_{50}$ value and Hill slope of $86.4 \mu \mathrm{M}$ and 1.17, respectively. $B$, Concentration-response curves in the absence (open squares) and presence (closed diamonds) of $\mathrm{S}(-)$ eticlopride (a $\mathrm{D}_{2}$-like antagonist). The resultant curve was shifted to the right to a small extent, in the presence of the $\mathrm{D}_{2}$-like antagonist; the estimated $\mathrm{IC}_{50}$ value and Hill slope were $15.0 \mu \mathrm{M}$ and 0.97 , respectively. All points depicted are the mean \pm SEM of pooled data from 3-19 cells. The maximum effect value in the presence of both antagonists was constrained to that observed in the absence of antagonist (i.e., $71.1 \%$ ). Note that the concentration-response curves of DA alone (open squares) are the same as those depicted in Figure 1.

evoked IPSCs (Fig. 4B,C); however, the inhibitory effect of DA on the amplitude of evoked IPSCs was still apparent (although reduced) if applied before the effect of forskolin had reached its plateau (3-7 min after application of forskolin), showing that forskolin had indeed occluded the inhibitory action of DA on GABAergic transmission.

\section{Presynaptic mechanism of DA on inhibitory transmission}

Effect of DA on miniature IPSCs

To examine directly whether the effect of DA on evoked IPSCs is mediated by a presynaptic mechanism, its action on mIPSCs was analyzed. MBF neurons exhibited spontaneous IPSCs in the presence of TTX $(0.5 \mu \mathrm{M})$, so they were probably true mIPSCs. The frequency of mIPSCs was rather low for analysis in the normal $\left(2.5 \mathrm{mM} \mathrm{CaCl}_{2}\right)$ Krebs solution. Therefore, the baseline frequency of mIPSCs was increased by raising the external $\mathrm{Ca}^{2+}$ concentration to $7.5 \mathrm{~mm}$ in the presence of $0.5 \mu \mathrm{M}$ TTX and $5 \mu \mathrm{M}$ CNQX, as shown in Figure $5 A$. The mean frequency of mIPSCs under these conditions was $0.61 \pm 0.11 \mathrm{~Hz}(n=11)$. The cell illustrated in Figure 5 had a mean mIPSC amplitude of $18.8 \pm 0.52 \mathrm{pA}(n=$ 190 events), as indicated in the amplitude histogram [Fig. 5C(a)]. There was no significant correlation between rise time (10-90\%) and mIPSC amplitude [Fig. 5C(b)], suggesting genuine variability in mIPSC amplitude rather than spatial dispersion. These mIPSCs were blocked by $10 \mu \mathrm{M}$ bicuculline (data not shown). The mean frequency of mIPSCs was reduced after 1 min exposure of $10 \mu \mathrm{M}$ DA and reached a steady level after 3 min (Fig. 5B). The amplitude histogram [Fig. $5 D(a)$ ] shows a $57.4 \%$ reduction in the total number of events, with no change in the mean amplitude of mIPSCs $(16.9 \pm 1.12 \mathrm{pA} ; n=81$ events) compared with the control value of $18.8 \mathrm{pA}$. The relationship between rise time and amplitude of mIPSCs also remained unchanged during DA application [Fig. $5 D(b)]$. Pooled data from six cells showed that $10 \mu \mathrm{M}$ DA reduced the frequency of mIPSC by $64.8 \pm 2.1 \%$, with no change in mean amplitude $(102.4 \pm 11.5 \%$ of their respective controls). The mean rise time and the mean decay time constant of mIPSCs remained essentially the same during DA $(10 \mu \mathrm{M})$ application $(104.0 \pm 3.9 \%$ and $106.3 \pm 6.1 \%$, respectively, of their controls). As shown in Figure $5 A, B$, DA $(10 \mu \mathrm{M})$ reduced the baseline noise level in most of the neurons tested; however, we did not investigate this phenomenon further in the present study.

To determine the contribution of voltage-sensitive calcium channels at GABAergic presynaptic terminals to DA-induced reduction of the inhibitory transmission, the effect of DA on mIPSCs in the presence of $100 \mu \mathrm{M}$ cadmium $\left(\mathrm{Cd}^{2+}\right)$, a calcium channel blocker, was studied. This concentration of $\mathrm{Cd}^{2+}$ has been reported to block presynaptic calcium channels (Umemiya and Berger, 1995). The results of these experiments are expressed as amplitude histograms and depicted in Figure $6 \mathrm{~A}$. In the presence of $\mathrm{Cd}^{2+}$, the frequency of mIPSCs was reduced without affecting their mean amplitudes, and in five cells tested, a mean reduction to $60.7 \pm 5.9 \%$ of their respective controls was observed. This finding suggests an apparent contribution of $\mathrm{Cd}^{2+}$ sensitive calcium influx to the spontaneous GABA release. Even in the presence of $100 \mu \mathrm{M} \mathrm{Cd}^{2+}$ (Fig. 6C), however, application of DA $(10 \mu \mathrm{M})$ still reduced the frequency of mIPSCs, with a mean reduction by $52.3 \pm 7.1 \%(n=5)$, which was not significantly $(p>0.18)$ different from the effect of DA in the absence of $\mathrm{Cd}^{2+}$ $(64.8 \pm 2.1 \% ; n=6)$.

\section{DISCUSSION}

The main findings in the present study are that DA inhibits GABAergic inhibitory transmission onto MBF neurons via presynaptic $\mathrm{D}_{1}$-like receptors and that DA-induced presynaptic effect is independent of $\mathrm{Ca}^{2+}$ entry from outside and may be mediated by a cAMP-dependent pathway.

Although the inhibition produced by DA on the frequency of mIPSCs, without affecting their mean amplitude, strongly suggests that DA acts presynaptically, the exact origin of the inhibitory synapses that contribute to the mIPSC distributions remains to be established. Previous morphological studies have demonstrated that GABAergic terminals make synaptic contacts with neurons in the basal forebrain region (Zaborszky et al., 1986; Chang et al., 1995) and that a large proportion of these terminals probably arise from the nucleus accumbens (Heimer et al., 1991; Zaborszky and Cullinan, 1992). The IPSCs recorded in the present study may therefore be evoked by stimulating these fibers, although some of the IPSCs might also be evoked by direct stimulation of GABAer- 

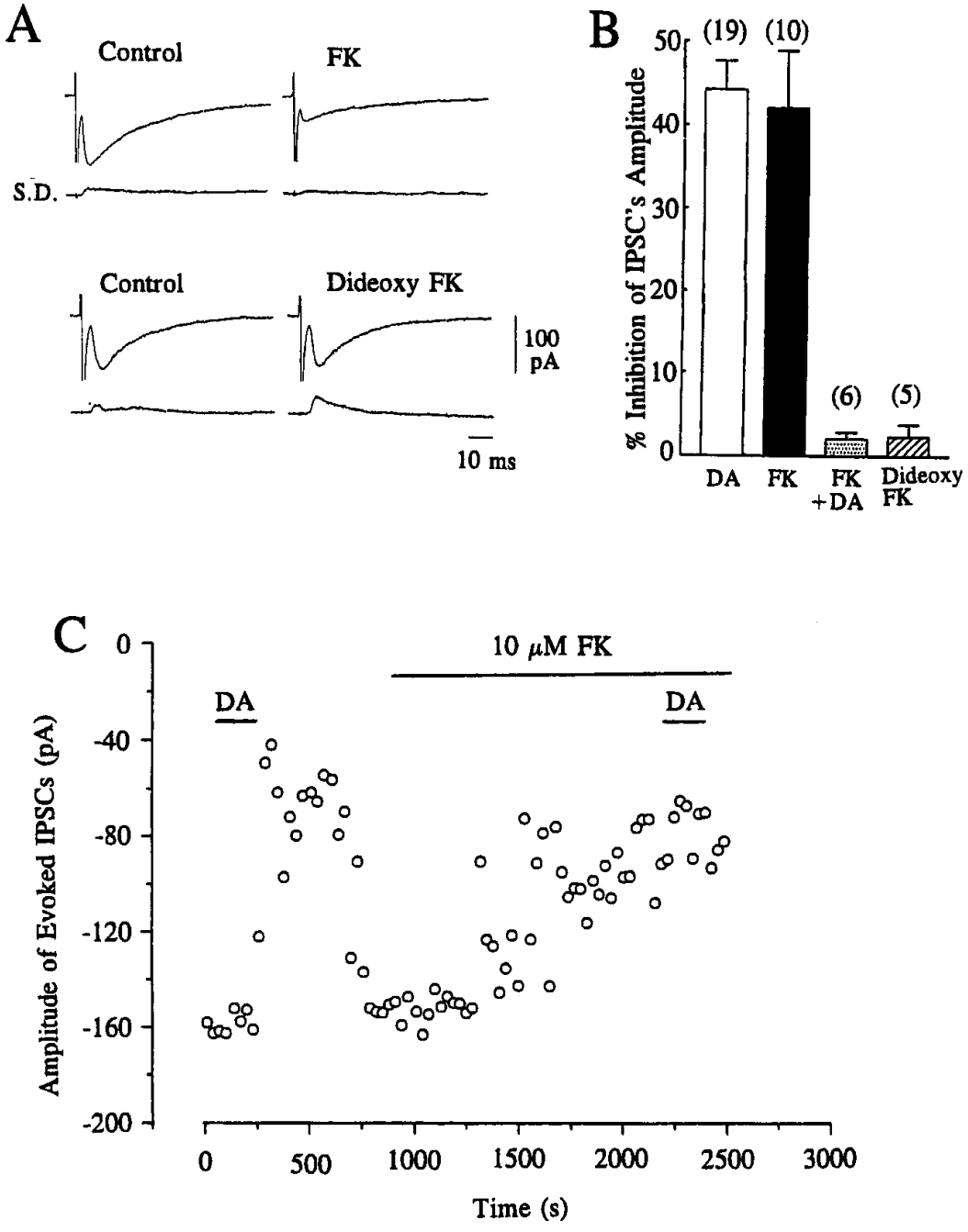

Figure 4. Effects of forskolin and 1,9-dideoxyforskolin on evoked IPSCs. $A$, Traces of evoked IPSCs showing the effect of forskolin $(F K)$ and 1,9-dideoxyforskolin (Dideoxy $F K$ ). Each trace is the average of 10 consecutive responses evoked at $0.1 \mathrm{~Hz}$ with the corresponding SD. Current traces showing the effect of FK and dideoxy FK were derived from different cells. $B$, Summary histograms representing mean \pm SEM of $\%$ inhibition of the amplitude of IPSCs by dopamine $(D A, 10$ $\mu \mathrm{M})$, by $F K(10 \mu \mathrm{M})$, by DA subsequent to $10-20 \mathrm{~min}$ perfusion of FK $(F K+D A)$, and by Dideoxy $F K$. Values were $44.3 \pm 3.4 \%(n=19), 42.1 \pm 6.8 \%(n=10), 2.1 \pm 0.76 \%$ $(n=6)$, and $2.4 \pm 1.5 \%(n=5)$, respectively. (The value for DA was derived from the concentration-response curve in Fig. 1.) There was no significant $(p>0.33)$ difference in the effect produced by DA compared with FK. The dideoxy FK-induced effect was significantly $(p<0.002)$ smaller than that of DA or FK. Application of $10 \mu \mathrm{M}$ DA after the effect of FK had reached a steady level (after 15-20 min) produced virtually no further effect on the inhibitory action on the amplitude of IPSCs, and the effect of DA in the presence of FK was significantly $(p<0.001)$ smaller than that of DA or FK applied alone. $C$, Time course of the inhibitory effect of FK $(10 \mu \mathrm{M})$ on the amplitude of evoked IPSCs and occlusion of the effect of DA $(10 \mu \mathrm{M})$ in the continuing presence of FK. IPSCs were evoked at $0.1 \mathrm{~Hz}$, and each point represents the mean amplitude of three consecutive responses. The holding potential was $-70 \mathrm{mV}$. gic neurons within basal forebrain nuclei, because some of the GABAergic terminals onto cholinergic neurons may arise from the local collaterals of intrinsic GABAergic neurons (Sun and Cassell, 1993).

The presynaptic inhibition of mIPSCs by DA remained unaffected in the presence of $\mathrm{Cd}^{2+}$, suggesting that DA produces its inhibitory effect on the release of GABA subsequent to calcium entry via voltage-sensitive calcium channels. Similar calciumindependent mechanisms to presynaptic inhibition have been observed in other brain regions, namely the inhibition of excitatory transmission by activation of muscarinic and metabotropic glutamate receptors in the hippocampus (Scanziani et al., 1995), $\mathrm{GABA}_{\mathrm{B}}$ receptors at a cerebellar synapse (Dittman and Regehr, 1996), and adenosine $A_{1}$ receptors in the hippocampus (Scholz and Miller, 1992), as well as in the reduction of inhibitory glycinergic transmission by the activation of $5-\mathrm{HT}_{1 \mathrm{~B}}$ receptors in the brain stem (Umemiya and Berger, 1995). In addition, a recent study has reported that activation of adenosine, $\mathrm{GABA}_{\mathrm{B}}$, or $\mu$-opioid receptors inhibits ionomycin, gadolinium or $\alpha$-latrotoxin-induced glutamate, and GABA release in a calciumindependent pathway (Capogna et al., 1996).

The present pharmacological results indicate that DA reduces inhibitory GABAergic synaptic transmission onto MBF neurons by a presynaptic mechanism that involves the activation of DA receptors with properties in common with $\mathrm{D}_{1}$ family, most notably from the antagonism by $\mathrm{R}(+)-\mathrm{SCH} 23380$. Although the apparent $K_{\mathrm{B}}$ value for $\mathrm{R}(+)-\mathrm{SCH} 23390$, a $\mathrm{D}_{1}$-like antagonist, in the present study $(0.82 \mu \mathrm{M})$ is higher than the binding constant for [ $\left.{ }^{3} \mathrm{H}\right] \mathrm{SCH} 23390$ to cloned $\mathrm{D}_{1}$ receptors $(0.3-0.35 \mathrm{~nm}$; cf. Sunahara et al., 1991) by three orders of magnitude, this antagonist has also been reported to show a 100 -fold higher $K_{\mathrm{B}}$ value $(40 \mathrm{~nm})$ against the functional (cyclase-stimulating) action of DA than that predicted from its binding constant in broken membrane preparations (Andersen et al., 1985). In addition, 1-100 $\mu \mathrm{M}$ of this antagonist was required to antagonize $\mathrm{DA}$ - or $\mathrm{D}_{1}$-like agonistinduced effect in previous electrophysiological studies using rat brain slices as well as cultured neurons, while still preserving selectivity over $\mathrm{D}_{2}$-like antagonists (Pennartz et al., 1992; Schiffmann et al., 1995; Harvey and Lacey, 1996; Nicola et al., 1996). Furthermore, another electrophysiological study using Helix has reported an estimated $\mathrm{pA}_{2}$ value for $\mathrm{SCH} 23390$ of 6.1 (HoldenDye and Walker, 1989) at pharmacologically characterized $\mathrm{D}_{1^{-}}$like receptors, which is comparable with our estimated $\mathrm{pK}_{\mathrm{B}}$ value. This requirement for higher concentrations in functional studies than those predicted by radioligand binding assays, coupled with the lesser effect of $\mathrm{D}_{2}$-like agonist and antagonist, indicates that the effect of $\mathrm{R}(+)-\mathrm{SCH} 23390$ in the present study can be attributed to a block of $\mathrm{D}_{1}$-like receptors rather than to any crossreactivity with $\mathrm{D}_{2}$-like receptors.

In our studies using agonists, however, namely R(-)-TNPA or 


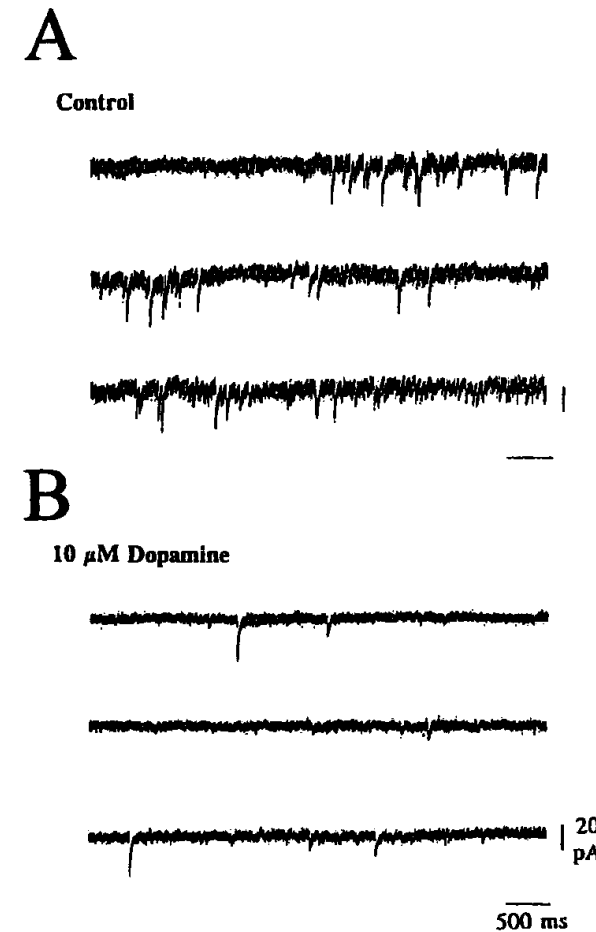

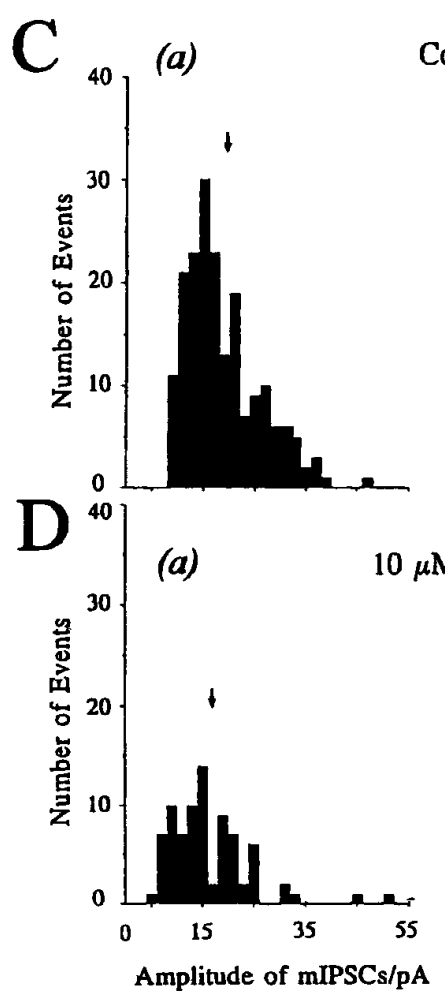

Control

(b)

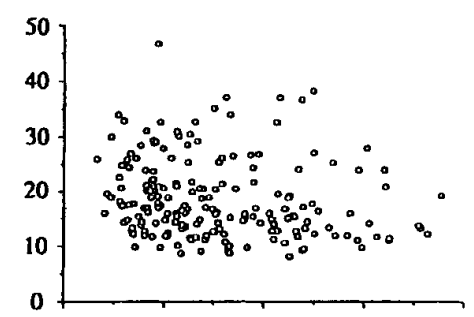

$\mu \mathrm{M}$ Dopamine

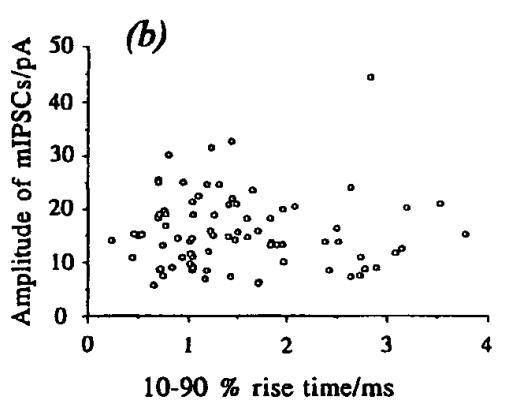

Figure 5. Effect of dopamine on spontaneous mIPSCs. mIPSCs were recorded in $7.5 \mathrm{~mm}$ external $\mathrm{CaCl}_{2} \mathrm{Krebs}$ solution containing TTX $(0.5 \mu \mathrm{M})$ and CNQX $(5 \mu \mathrm{M}) . A, B$, Consecutive traces taken in control $(A)$ and 3 min after application of $10 \mu \mathrm{M}$ dopamine $(B)$. Note that DA (10 $\mu \mathrm{M})$ reduced the baseline noise level. $C(a), D(a)$, Amplitude histograms derived from 4 min stretches (bin width, $2.0 \mathrm{pA}$ ) of mIPSCs in control [C(a), 190 events] and dopamine $[D(a), 81$ events] sampled 3-7 min after application of dopamine. Arrows indicate the mean amplitude of mIPSCs (18.8 pA in control and 16.9 pA after application of dopamine). $C(b), D(b)$, Rise time (10-90\%)/amplitude relation of mIPSCs before $[C(b)]$ and after application of dopamine $[D(b)]$. Control: mean rise time $=3.03 \pm 0.11$ msec; mean decay time constant $=12.66 \pm 0.55$ msec. Dopamine: mean rise time $=3.02 \pm 0.18$ msec; mean decay time constant $=14.78 \pm 0.89 \mathrm{msec}$. The holding potential was $-70 \mathrm{mV}$.

(-)-quinpirole, these $\mathrm{D}_{2}$-like agonists had little or no effect on the amplitude of IPSCs. In contrast, the use of S(-)-eticlopride, a $\mathrm{D}_{2}$-like antagonist, induced a small antagonism on the concentration-response curve to DA. Because S(-)-eticlopride did not display any apparent antagonism to DA-mediated inhibition of excitatory transmission within these nuclei (Momiyama et al., 1996), the present finding seemed to suggest that a possible (but to a lesser extent) contribution of $\mathrm{D}_{2}$-like receptors to the depression of evoked IPSCs cannot be excluded completely. In the present study, however, simultaneous application of both $\mathrm{D}_{1}$-like and $\mathrm{D}_{2}$-like agonists showed no different effect from that induced by $\mathrm{D}_{1}$-like agonist alone, indicating no apparent interaction between $\mathrm{D}_{1}$-like and $\mathrm{D}_{2}$-like receptors.

One interesting finding of the present study is the observation that the application of forskolin reduced the amplitude of the evoked IPSCs by itself. This action of forskolin occluded the inhibitory effect of DA on IPSCs, because DA applied in the presence of forskolin evoked no further reduction in the amplitude of evoked IPSCs. Because forskolin stimulates adenylate cyclase and increases $[\mathrm{cAMP}]_{\mathrm{i}}$ levels, and $\mathrm{D}_{1}$-like receptors have been classified as those positively coupled to adenylate cyclase activity (Kebabian and Calne, 1979), these results provide further support for the role of $\mathrm{D}_{1}$-like receptors for the inhibition of GABAergic inhibitory transmission. The present finding that forskolin inhibits IPSCs in MBF neurons, however, contrasts with previous studies at other synapses where forskolin has been reported to enhance inhibitory synaptic transmission (Llano and Gerschenfeld, 1993; Capogna et al., 1995). One possible explana- tion for this opposing action of forskolin may be explained by differences in presynaptic mechanisms in different brain regions under study, but additional studies are necessary to clarify the precise mechanisms.

Although $\mathrm{D}_{1}$-like receptor-mediated facilitation of GABA release has been reported in putative DA-containing neurons in the ventral tegmental area (Cameron and Williams, 1993), the present finding that $D_{1}$-like receptors are involved in mediating inhibition of the release of GABA to increase cellular excitability within basal forebrain nuclei correlates well with data of a previous report that DA attenuated the inhibitory action of iontophoretic application of GABA (Bergstrom and Walters, 1984). On the other hand, presynaptic $\mathrm{D}_{1}$-like receptors have also been reported to be involved in the inhibition of excitatory transmission in these basal forebrain neurons (Momiyama et al., 1995a; 1996) as well as in nucleus accumbens (Pennartz et al., 1992; Harvey and Lacey, 1996; Nicola et al., 1996). The role of $\mathrm{D}_{1}$-like receptors in modulating both excitatory and inhibitory inputs onto magnocellular neurones suggests that DA has a role in regulating the balance between excitation and inhibition within basal forebrain nuclei. Indeed, such dual actions of DA is reflected in the findings of a previous electrophysiological study using anesthetized rats (Napier and Maslowski-Cobuzzi, 1994) in which neuronal activity in the ventral pallidum can be variably inhibited or excited by iontophoretic application of DA.

In conclusion, the results of the present study strongly suggest that DA projections to basal forebrain nuclei play an important role in controlling the activity of inhibitory transmission onto 

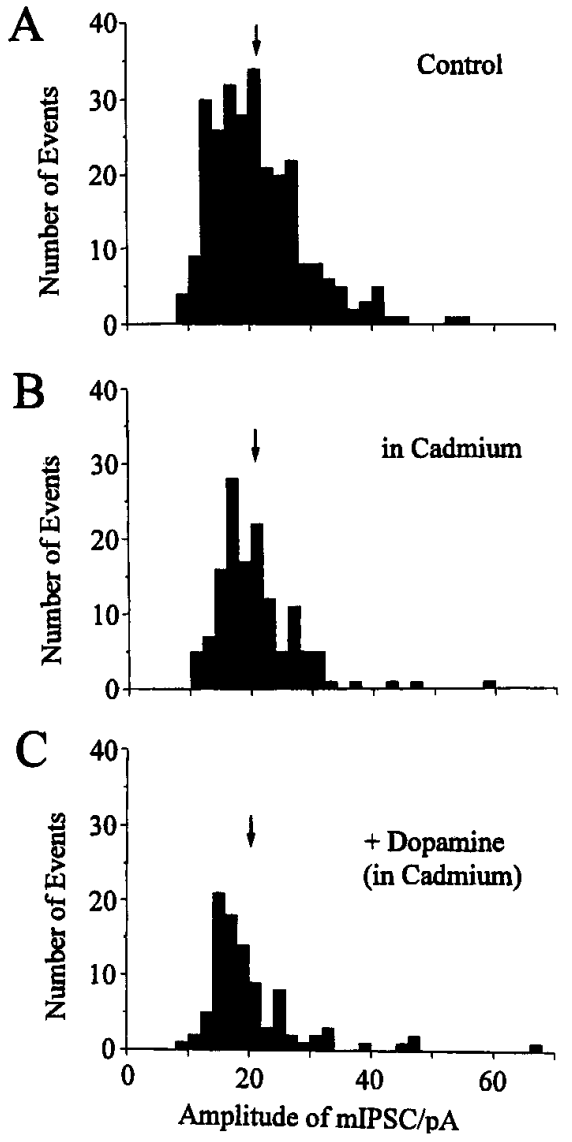

Figure 6. Effect of cadmium on mIPSCs. Amplitude histograms derived from 4 min stretches (bin width, $2.0 \mathrm{pA}$ ) in control ( $A, 267$ events), in the presence of $100 \mu \mathrm{M}$ cadmium ( $B, 138$ events), and after $10 \mu \mathrm{M}$ dopamine ( $C, 94$ events) in the continuing presence of cadmium. Arrows indicate the mean amplitudes of mIPSCs in control, in cadmium, and in dopamine/ cadmium $(21.5,20.7$, and $20.5 \mathrm{pA}$, respectively). mIPSCs were recorded in $7.5 \mathrm{mM} \mathrm{CaCl}_{2}, 0.5 \mu \mathrm{M}$ TTX, and $5 \mu \mathrm{M}$ CNQX at a holding potential of $-70 \mathrm{mV}$.

cholinergic basal forebrain neurons to increase cellular excitability. Coupled with our previous findings on excitatory transmission (Momiyama et al., 1996), however, the action of DA is neither an "excitatory" nor an "inhibitory" transmitter in basal forebrain nuclei. Indeed, the dopaminergic inputs terminating onto magnocellular neurons seemed to play more of a role in controlling the balance between excitatory and inhibitory synaptic circuitry of these cortically projecting nuclei. From a pathophysiological point of view, the present findings also raise the possibility that dopaminergic systems might also be involved in some of the defects in cognition and memory in various neurodegenerative diseases, including Alzheimer's disease or senile dementia, as well as Parkinson's disease, schizophrenia, or drug abuse.

\section{REFERENCES}

Andersen PH, Jansen JA (1990) Dopamine receptor agonists: selectivity and dopamine $\mathrm{D}_{1}$ receptor affinity. Eur J Pharmacol 188:335-347.

Andersen PH, Gronvald FC, Jansen JA (1985) A comparison between dopamine-stimulated adenylate cyclase and ${ }^{3} \mathrm{H}-\mathrm{SCH} 23390$ binding in rat striatum. Life Sci 37:1971-1983.

Bergstrom DA, Walters JR (1984) Dopamine attenuates the effect of GABA on single unit activity in the globus pallidus. Brain Res 310:23-33.

Cameron DL, Williams JT (1993) Dopamine D1 receptors facilitate transmitter release. Nature 366:344-347.
Capogna M, Gähwiler BH, Thompson SM (1995) Presynaptic enhancement of inhibitory synaptic transmission by protein kinase $\mathrm{A}$ and $\mathrm{C}$ in the rat hippocampus in vitro. J Neurosci 15:1249-1260.

Capogna M, Gähwiler BH, Thompson SM (1996) Presynaptic inhibition of calcium-dependent and -independent release elicited with ionomycin, gadolinium, and $\alpha$-latrotoxin. J Neurophysiol 75:2017-2028.

Chang HT, Tian Q, Herron P (1995) GABAergic axons in the ventral forebrain of the rat: an electron microscopic study. Neuroscience 68:207-220.

Coyle JT, Price DL, DeLong MR (1983) Alzheimer's disease: a disorder of cortical cholinergic innervation. Science 219:1184-1190.

Dittman JS, Regehr WG (1996) Contribution of calcium-dependent and calcium-independent mechanisms to presynaptic inhibition at a cerebellar synapse. J Neurosci 16:1623-1633.

Eaton MJ, Wagner CK, Moore KE, Lokkingland KJ (1994) Neurochemical identification of $\mathrm{A}_{13}$ dopaminergic neuronal projections from the medial zona interna to the horizontal limb of the diagonal band of Broca and the central nucleus of the amygdala. Brain Res 659:201-207.

Gao Y, Baldessarini RJ, Kula NS, Neumeyer JL (1990) Synthesis and dopamine receptor affinities of enantiomers of 2-substituted apomorphines and their $N$ - $n$-propyl analogues. J Med Chem 33:1800-1805.

Hall H, Kohler C, Gawell L (1985) Some in vitro receptor binding properties of $\left[{ }^{3} \mathrm{H}\right]$-eticlopride, a novel substituted benzamide, selective for dopamine $\mathrm{D}_{2}$ receptors in the rat brain. Eur J Pharmacol 111:191-199.

Harvey J, Lacey MG (1996) Endogenous and exogenous dopamine depress EPSCs in rat nucleus accumbens in vitro via $\mathrm{D}_{1}$ receptor activation. J Physiol (Lond) 492:143-154.

Heimer L, Zahm DS, Churchill L, Kalivas PW, Wohtmann C (1991) Specificity in the projection patterns of accumbal core and shell in the rat. Neuroscience 41:89-125.

Holden-Dye L, Walker RJ (1989) Further characterization of the dopamine-inhibitory receptor in helix and evidence for a noradrenalinepreferring receptor. Comp Biochem Physiol 93C:413-419.

Iorio LC, Barnett A, Leitz FH, Houser VP, Korduba CA (1983) SCH 23390, a potential benzazepine antipsychotic with unique interactions on dopaminergic system. J Pharmacol Exp Ther 226:462-468.

Jonas P, Major G, Sakmann B (1993) Quantal components of unitary EPSCs at the mossy fibre synapse on CA3 pyramidal cells of rat hippocampus. J Physiol (Lond) 472:615-663.

Kebabian JW, Calne DB (1979) Multiple receptors for dopamine. Nature 277:93-96.

Llano I, Gerschenfeld HM (1993) $\beta$-adrenergic enhancement of inhibitory synaptic activity in rat cerebellar stellate and Purkinje cells. J Physiol (Lond) 468:201-224.

Martinez-Murillo R, Semenko F, Cuello AC (1988) The origin of tyrosine hydroxylase-immunoreactive fibers in the region of the nucleus basalis magnocellularis of the rat. Brain Res 451:227-236.

Momiyama T, Sim JA, Brown DA (1995a) Presynaptic inhibition of excitatory inputs to rat magnocellular basal forebrain neurones by dopamine. J Physiol (Lond) 487.P:50P.

Momiyama T, Sim JA, Brown DA (1995b) Dopaminergic inhibition of synaptic currents in cholinergic magnocellular neurons in the basal forebrain. Soc Neurosci Abstr 21:1091.

Momiyama T, Sim JA, Brown DA (1996) Dopamine $\mathrm{D}_{1}$-like receptormediated presynaptic inhibition of excitatory transmission onto rat magnocellular basal forebrain neurones. J Physiol (Lond) 495:97-106.

Napier TC, Malowski-Cobuzzi RJ (1994) Electrophysiological verification of the presence of D1 and D2 dopamine receptors within the ventral pallidum. Synapse 17:160-166.

Nicola SM, Kombian SB, Malenka RC (1996) Psychostimulants depress excitatory synaptic transmission in the nucleus accumbens via presynaptic $\mathrm{D}_{1}$-like dopamine receptors. J Neurosci 16:1591-1604.

Oyanagi K, Takahashi H, Wakabayashi K, Ikuta F (1989) Correlative decrease of large neurons in the neostriatum and basal nucleus of Meynert in Alzheimer's disease. Brain Res 504:354-357.

Pennartz CMA, Dolleman-Van Der Weel MJ, Kitai ST, Lopes Da Silva FH (1992) Presynaptic dopamine D1 receptors attenuate excitatory and inhibitory limbic inputs to the shell region of the rat nucleus accumbens studied in vitro. J Neurophysiol 67:1325-1334.

Rye DB, Wainer BH, Mesulam M-M, Mufson EJ, Saper CB (1984) A study of cholinergic and noncholinergic components employing combined retrograde tracing and immunohistochemical localization of choline acetyltransferase. Neuroscience 13:627-643.

Scanziani M, Gähwiler BH, Thompson SM (1995) Presynaptic inhibition of excitatory synaptic transmission by muscarinic and metabotropic 
glutamate receptor activation in the hippocampus: are $\mathrm{Ca}^{2+}$ channels involved? Neuropharmacology 34:1549-1557.

Schiffmann SN, Lledo P-M, Vincent J-D (1995) Dopamine $\mathrm{D}_{1}$ receptor modulates the voltage-gated sodium current in rat striatal neurones through a protein kinase A. J Physiol (Lond) 483:95-107.

Scholz KP, Miller RJ (1992) Inhibition of quantal transmitter release in the absence of calcium influx by a $\mathrm{G}$ protein-linked adenosine receptor at hippocampal synapses. Neuron 8:1139-1150.

Semba K, Reiner PB, McGeer EG, Fibiger HC (1988) Brainstem afferents to the magnocellular basal forebrain studied by axonal transport, immunohistochemistry, and electrophysiology in the rat. J Comp Neurol 267:433-453.

Sim JA (1994) Maintained morphology of rat magnocellular cholinergic basal forebrain neurones in culture. J Physiol (Lond) 480.P:34P.

Sim JA, Griffith WH (1996) Muscarinic inhibition of glutamatergic transmission onto rat magnocellular basal forebrain neurones in a thin-slice preparation. Eur J Neurosci 8:880-891.

Stern P, Edwards FA, Sakmann B (1992) Fast and slow components of unitary EPSCs on stellate cells elicited by focal stimulation in slices of rat visual cortex. J Physiol (Lond) 449:247-278.

Sun N, Cassell MD (1993) Intrinsic GABAergic neurons in the rat central extended amygdala. J Comp Neurol 330:381-404.
Sunahara RK, Guan H-C, O'Dowd BF, Seeman P, Laurier LG, Gordon NG, George SR, Torchia J, Van Tol HHM, Niznik HB (1991) Cloning of the gene for a human dopamine $\mathrm{D}_{5}$ receptor with higher affinity for dopamine than $\mathrm{D}_{1}$. Nature 350:614-619.

Takahashi T (1992) The minimal inhibitory synaptic currents evoked in neonatal rat motoneurones. J Physiol (Lond) 450:593-611.

Titus RD, Korndeld EC, Jones ND, Clemens JA, Smalstig EB, Fuller RW, Hahn RA, Hynes MD, Mason NR, Wong DT, Foreman MM (1983) The resolution and absolute configuration of an ergoline-related dopamine agonist, trans-4,4a5,6,7,8,8a,9-octahydro-5-propyl-1H-pyrazolo[3,4-g]quinoline. J Med Chem 26:1112-1116.

Umemiya M, Berger AJ (1995) Presynaptic inhibition by serotonin of glycinergic inhibitory synaptic currents in the rat brain stem. J Neurophysiol 73:1192-1200.

Zaborszky L, Cullinan WE (1992) Projections from the nucleus accumbens to cholinergic neurons of the ventral pallidum: a correlated light and electron microscopic double-immunolabeling study in rat. Brain Res 570:92-101.

Zaborszky L, Heimer L, Eckenstein F, Leranth C (1986) GABAergic input to cholinergic forebrain neurons: an ultrastructural study using retrograde tracing of HRP and double immunolabeling. J Comp Neurol 250:282-295. 